\title{
Design of Miniaturized SIW Filter Loaded with Open-Loop Resonators and its Application to Diplexer
}

\author{
Rusan Kumar BARIK ${ }^{1}$, Qingsha S. CHENG ${ }^{1,2}$, Nrusingha Charan PRADHAN ${ }^{3}$, \\ Sholampettai Submaranian KARTHIKEYAN ${ }^{3}$ \\ ${ }^{1}$ Dept. of Electrical and Electronic Engineering, Southern University of Science and Technology, Shenzhen, 518055, China \\ ${ }^{2}$ University Key Laboratory of Advanced Wireless Communications of Guangdong Province, \\ Southern University of Science and Technology, Shenzhen, 518055, China \\ ${ }^{3}$ Dept. of Electronics and Communication Engineering, National Institute of Technology, Tiruchirappalli, \\ Tamil Nadu-620015, India
}

rusanbarik@gmail.com, chengqs@ sustech.edu.cn, nrusinghapradhan01@gmail.com, sskarthikeyan@nitt.edu

Submitted June 20, 2020 / Accepted September 1, 2020

\begin{abstract}
This paper presents a novel design of miniaturized substrate-integrated waveguide (SIW) filter loaded with a pair of unit-cell resonators. Two identical open-loop resonators are connected face-to-face to form a unit-cell. A pair of unit-cells is engraved on the surface of the SIW to develop an evanescent-mode bandpass filter. The proposed unit-cells behave as an electric-dipole and produce a passband smaller than the waveguide frequency. This reduction in resonant frequency allows us to achieve size miniaturization. An equivalent electrical-circuit model is developed and investigate for characterization of passband and transmission-zero. This filter structure is then employed to develop a SIW planar diplexer. Two SIW filter structures loaded with unit-cells are excited with a T-shaped feed line to achieve lower and upper channels of the diplexer. To demonstrate the analysis, both SIW filter and diplexer loaded with open-loop resonators are implemented and fabricated. The proposed SIW filter and diplexer prototypes exhibit size miniaturization, low insertion-loss and high-selectivity due to evanescent-mode transmission and sub-wavelength resonators. The measurement responses are very similar to the simulation responses.
\end{abstract}

\section{Keywords}

SIW, filter, diplexer, open-loop resonator

\section{Introduction}

Substrate-integrated waveguide (SIW) is a promising technology for development of compact and highperformance filters for advanced wireless applications. This technology exhibits advantages such as low loss, high Qfactor, smaller size, low cost and ease integration with other microwave devices. Bandpass filter is an inevitable candidate in advanced RF/microwave front-end systems [1]. The design of bandpass filters and diplexers employing SIW provides high Q-factor and good selectivity. But the conventional SIW occupies relatively large circuit-area [2].

In order to achieve miniaturization, several new techniques are developed to design compact SIW bandpass filters [3-14]. In [3], the folded and ridged SIWs are employed to design an evanescent-mode bandpass filter. In [4], a SIW bandpass filter is implemented using modified doublet with high Q-factor. A miniaturized bandpass filter is implemented based on SIW with complementary split-ring resonator (CSRR) [5]. In [6], defected-ground structure is employed with SIW to implement a miniaturized filter. In [7], a filter is designed using tri-section SIW with an interdigital structure on its top surface. The higher-order mode suppressed bandpass filters using $\mathrm{TM}_{02}$ [8] and multi-layer [9] are developed based on SIW. In [10], miniaturized SIW bandpass filter is implemented using a stepped-impedance non-resonating node. In [11], a highly-selective bandpass filter based on SIW is realized employing higher order $\mathrm{TE}_{301}$ resonators. Degenerated and resonating modes are used to develop a bandpass filter based on a single circular cavity [12]. In [13], a SIW bandpass filter is developed by using stepped-impedances. In [14], a design approach is investigated for filters based on SIW electromagnetic bandgap.

Furthermore, several filter structures based on microstrip and SIW are employed to design planar diplexers [15-27]. A compact diplexer is developed by utilizing the multiple resonant modes in the SIW cavity [15]. In [16], a compact SIW diplexer is designed by applying dual-mode junction cavity for K-band application. In [17], a compact SIW diplexer is implemented based on common dual-mode cavity junction with flexible bandwidth. Dual-mode SIW filter structures are combined by a T-junction to develope a planar diplexer in [18]. In [19], dual-mode SIW resonators 
are combined together to design a compact diplexer. In [20], a planar microstrip diplexer is realized based on direct coupling. A SIW diplexer is designed employing input/output coupling in [21]. In [22], a three-state diplexer is developed based on SIW. In [23], a diplexer based on SIW is realized using dual-mode resonator with high isolation. In [24], a SIW diplexer with tunable characteristic is designed for high isolation. Mixed electric and magnetic coupling is used to realized a SIW diplexer with high isolation in [25]. In [26], a diplexer based on SIW square cavities is developed for C-band applications. In [27], a SIW diplexer is realized based on mode suppression technique. It is observed that the isolation is larger in [17-21], [23-25] and smaller in [15, 16, $22,26,27]$. Also, it is noted that these diplexers occupy larger circuit area with large insertion loss. However, performance improvement, design flexibility and highly miniaturization of SIW diplexer with low insertion loss and more bandwidth are possible, which needs to be investigated.

In this paper, design of a novel miniaturized filter implemented on substrate-integrated waveguide (SIW) is presented. This filter is developed using conventional SIW loaded with two identical unit-cell resonators. The unit-cell is formed by connecting two open-loop resonators. The proposed filter generates an evanescent-mode transmission by introducing the unit-cell resonators and produces a passband smaller than the waveguide frequency due to its electricdipole characteristic. This reduction in operating frequency allow us to achieve size miniaturization. The filter responses are investigated using an equivalent circuit-model. This filter structure is then applied to design a compact SIW diplexer. To support our claim, miniaturized SIW bandpass filter and diplexer are implemented, fabricated and tested. The proposed prototypes achieve smaller size, low insertion loss, high selectivity, good out-of-band response and isolation.

This article is organized as follows. Configuration of the SIW filter, equivalent-circuit analysis, transmission responses, calculation of losses, Q-factor and miniaturization factor are discussed in section 2. Section 3 presents the development, fabrication and demonstration of SIW filter. Section 4 presents the development and fabrication of SIW diplexer. Section 5 concludes the key features of the proposed work.

\section{Configuration and Analysis of Pro- posed Filter}

Configuration, equivalent electrical-model followed by transmission responses and working principle of the proposed open-loop resonators (ORLs) loaded SIW Filter are investigated and presented in this section. A detailed analysis is carried-out for determination of losses, $Q_{\mathrm{e}}$ factor and miniaturization factor at the end of this section.

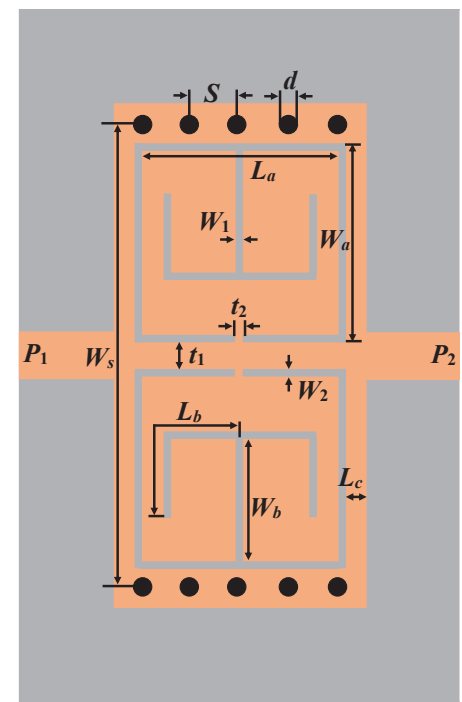

Fig. 1. Geometry of the proposed SIW bandpass filter. The layout dimensions are: $W_{\mathrm{s}}=18 \mathrm{~mm}, s=2 \mathrm{~mm}, d=1 \mathrm{~mm}$, $L_{\mathrm{a}}=9 \mathrm{~mm}, W_{\mathrm{a}}=8 \mathrm{~mm}, L_{\mathrm{b}}=2 \mathrm{~mm}, W_{\mathrm{b}}=2 \mathrm{~mm}$, $L_{\mathrm{c}}=0.5 \mathrm{~mm}, W_{1}=0.3 \mathrm{~mm}, W_{2}=0.3 \mathrm{~mm}, t_{1}=0.6 \mathrm{~mm}$, $t_{2}=0.3 \mathrm{~mm}$.

Figure 1 shows the geometry of the proposed SIW bandpass filter. The electric side-walls of the SIW are formed by two linear arrangement of the metallic-vias. A pair of OLRs arranged face-to-face are introduced and engraved on the top of SIW. It is to be noted that the OLRs could be engraved on the ground.

However, it is required to maintain the integrity of ground at high-frequency in order to reduce the radiation-loss and insertion-loss. Two microstrip-lines having impedance of $50 \Omega$ are used as feedlines. Rogers RT/Duroid 5870 with its thickness of $0.787 \mathrm{~mm}, \tan \delta=0.0012$ and $\epsilon_{r}=2.33$ is used for this design. The SIW cavity is developed based on the formulas expressed in [2]. The diameter of $1 \mathrm{~mm}$ and centerto-center distance of $2.0 \mathrm{~mm}$ are chosen for this design. The width of the SIW is chosen as $18.0 \mathrm{~mm}$ to fix the cut-off frequency at $5.62 \mathrm{GHz}$.

\subsection{Equivalent-Circuit Analysis}

Figure 2 illustrates the $L C$-model of the proposed openloop resonators. The OLR can be represented as a tank-circuit modelled by $L_{\mathrm{r}}$ and $C_{\mathrm{r}}$. As two OLRs are connected back-toback, the mutual-coupling between them is modeled by $L_{\mathrm{ci}}$ and $C_{\mathrm{ci}}$. The resonating frequency of the OLRs are computed by using the parameters $L_{\mathrm{a}}, W_{\mathrm{a}}, L_{\mathrm{b}}, W_{\mathrm{b}}, W_{1}$ and $W_{2}$.

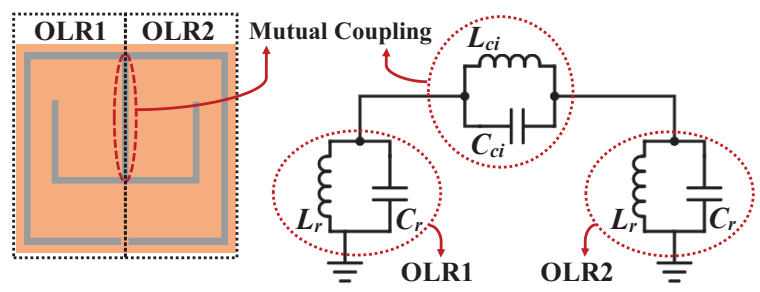

Fig. 2. Configuration of the proposed open-loop resonator and its equivalent circuit-model. 


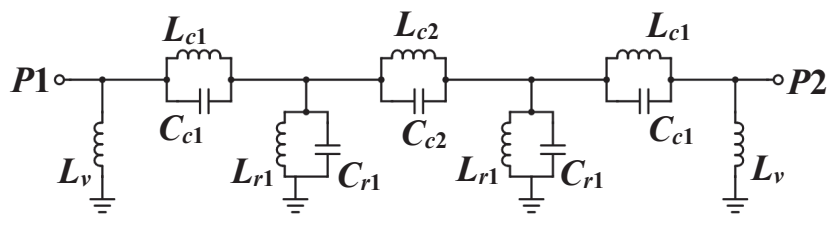

Fig. 3. Equivalent circuit-model of the proposed SIW bandpass filter. The electrical parameters are: $L_{\mathrm{V}}=4.123 \mathrm{nH}$, $L_{\mathrm{c} 1}=1.828 \mathrm{nH}, \quad C_{\mathrm{c} 1}=1.02 \mathrm{pF}, \quad L_{\mathrm{c} 2}=0.2 \mathrm{nH}$, $C_{\mathrm{c} 2}=0.1 \mathrm{pF}, L_{\mathrm{r} 1}=2.844 \mathrm{nH}, C_{\mathrm{r} 1}=4.04 \mathrm{pF}$.

As depicted in Fig. 3, the equivalent electrical-circuit of the OLRs loaded SIW filter is developed and analysed. The linearly arranged metallic-vias are modelled as shuntconnected inductor $L_{\mathrm{v}}$. The input-coupling results from both electrical and magnetic-coupling is denoted by $L_{\mathrm{c} 1}$ and $C_{\mathrm{c} 1}$. $L_{\mathrm{c} 1}$ represents the magnetic coupling realized through the split of the outer ring between the OLRs and waveguide transmission-line. The capacitive coupling is developed by the slot coupling between the OLRs and waveguide transmission line, as indicated by $C_{\mathrm{c} 1} . L_{\mathrm{r} 1}$ and $C_{\mathrm{r} 1}$ describe the OLRs. The mutual-coupling between OLRs is represented by $L_{\mathrm{c} 2}$ and $C_{\mathrm{c} 2}$. The circuit parameters of the proposed SIW bandpass filter is determined as: $L_{\mathrm{v}}=4.123 \mathrm{nH}, L_{\mathrm{c} 1}=1.828 \mathrm{nH}$, $C_{\mathrm{c} 1}=1.02 \mathrm{pF}, L_{\mathrm{c} 2}=0.2 \mathrm{nH}, C_{\mathrm{c} 2}=0.1 \mathrm{pF}, L_{\mathrm{r} 1}=2.844 \mathrm{nH}$, $C_{\mathrm{r} 1}=4.04 \mathrm{pF}$.

\subsection{Transmission Responses}

The full-wave simulated and circuit-model transmission responses of the proposed filter are illustrated in Fig. 4 along with the optimized geometry dimensions and electricalcircuit parameters. From the figure, it is seen that the passband of the proposed filter $(1.84 \mathrm{GHz})$ is below the SIW cut-off frequency $(5.62 \mathrm{GHz})$. Also, a transmission zero is produced at $3.68 \mathrm{GHz}$ and controlled by the input-coupling. This Transmission Zero (TZ) can be tuned by varying the input-coupling elements at frequency:

$$
f_{\mathrm{TZ}}=\frac{1}{2 \pi \sqrt{L_{\mathrm{c} 1} C_{\mathrm{c} 1}}} .
$$

The position of the TZ can be shifted towards passband by increasing the parameters $L_{\mathrm{c} 1}$ and $C_{\mathrm{c} 1}$. Figure 5 depicts the E-field propagation of the proposed OLR loaded SIW filter. The variations of $\left|S_{21}\right|$ as a function of $L_{a}$ and $W_{\text {a }}$ are illustrated in Fig. 6. The passband can be tuned to lower frequency by increasing the values of $L_{\mathrm{a}}$ and $W_{\mathrm{a}}$. From Fig. 6(a), it is observed that there is negligible shift of transmission-zero by varying $L_{\mathrm{a}}$. When $W_{\mathrm{a}}$ increases, a strong input coupling is exists, which shifts the TZ towards the passband of the filter as seen in Fig. 6(b).

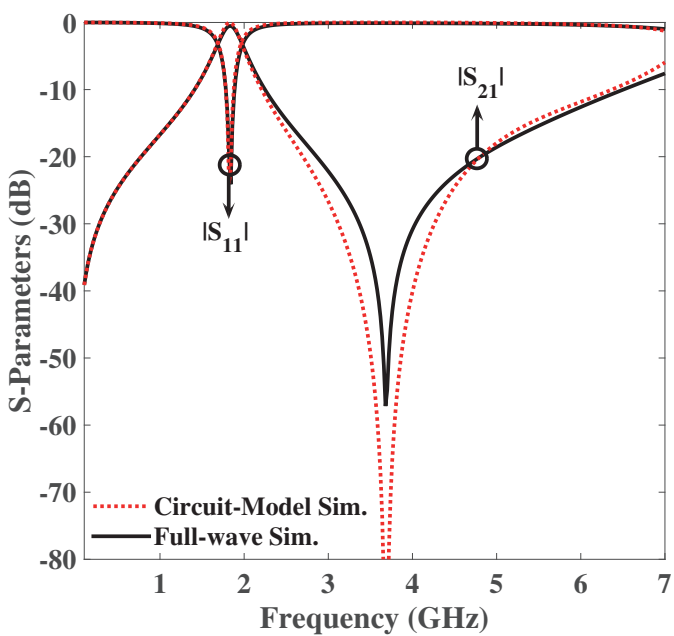

Fig. 4. Circuit-model and full-wave simulation responses.

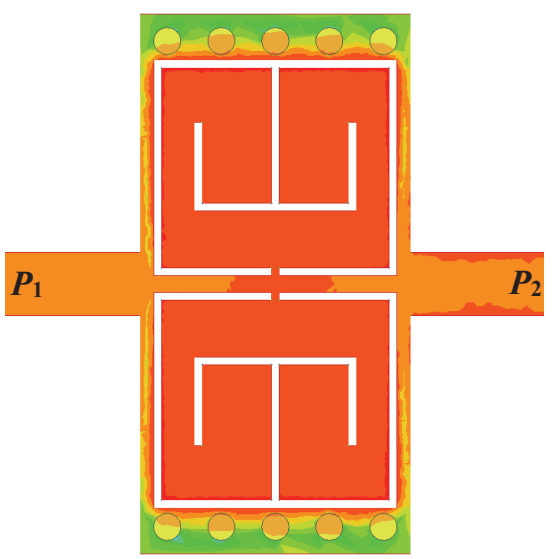

Fig. 5. E-field propagation of the proposed SIW filter.

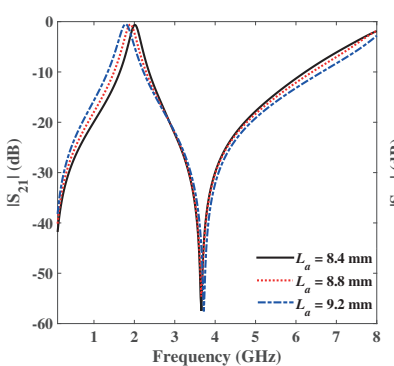

(a)

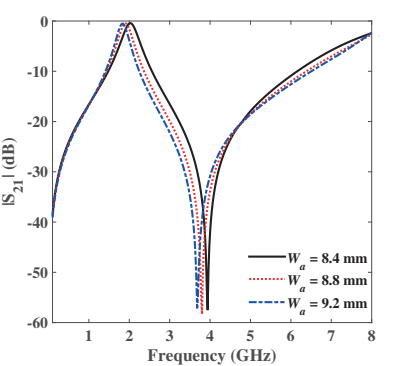

(b)
Fig. 6. Variation of the transmission response with respect to parameters: (a) $L_{\mathrm{a}}$. (b) $W_{\mathrm{a}}$.

\subsection{Loss and Q-Factor Calculations}

Since the proposed OLRs are not fully-closed geometry, the radiation-loss becomes a practical issue. Therefore, the losses (total loss, dielectric + conductor loss and radiation loss only) are investigated for the OLR loaded SIW filter as depicted in Fig. 7(a). It is observed that the radiation loss is not significant for the filter.

The normalized total loss and radiation-loss are calculated as 0.108 and 0.038 , respectively, which results to a $0.51 \mathrm{~dB}$ insertion loss for the proposed filter. 


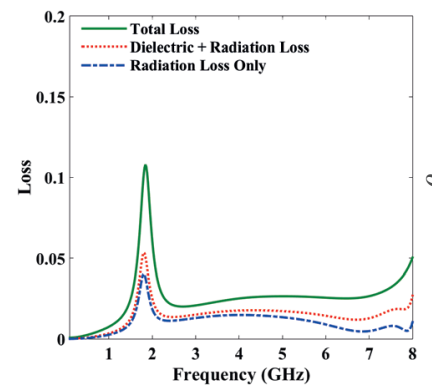

(a)

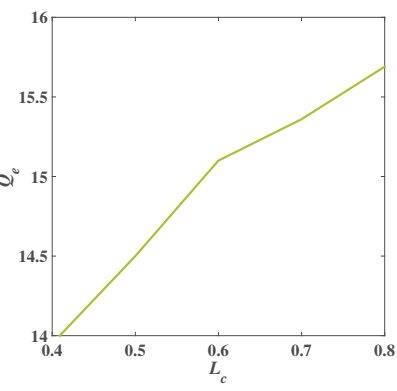

(b)
Fig. 7. (a) Loss calculation and (b) Computed Q-factor of the proposed filter.

The external Q-factor $\left(Q_{\mathrm{e}}\right)$ of the proposed OLR loaded SIW filter can be numerically determined based on the formula expressed in [1] as:

$$
Q_{\mathrm{e}}=\frac{2 f_{0}}{\Delta f_{3-\mathrm{dB}}}
$$

where $f_{0}$ and $\Delta f_{3-\mathrm{dB}}$ are the resonating frequency and 3-dB fractional bandwidth of the OLR loaded SIW filter, respectively. Figure 7(b) depicts the calculation $Q_{\mathrm{e}}$ by varying the dimension $L_{\mathrm{c}}$. It is observed that the value of $Q_{\mathrm{e}}$ increases by increasing the value of $L_{\mathrm{c}}$. At $f_{0}$, the $Q_{\mathrm{e}}$ of the proposed filter is determined as 14.5 .

\subsection{Miniaturization Factor}

The miniaturization factor (MF) for the proposed OLR loaded SIW filter is expressed as:

$$
M F \%=\frac{A_{\text {SIW } @ f_{\mathrm{r}}}-A_{\text {Proposed }}}{A_{\text {SIW } @ f_{\mathrm{r}}}} \times 100
$$

where $A_{\mathrm{SIW} @ f_{\mathrm{r}}}$ is the area of the conventional SIW geometry operating at fundamental frequency $f_{\mathrm{r}}$ and $A_{\text {Proposed }}$ is the area of the proposed OLR loaded SIW topology at $f_{0}$. The variation of MF with respect to the dimensions $\left(L_{\mathrm{a}}\right.$ and $\left.W_{\mathrm{a}}\right)$ of OLR loaded SIW filter is depicted in Fig. 8. From the figure, it is observed that the MF increases by increasing $L_{\mathrm{a}}$ and $W_{\mathrm{a}}$. When $L_{\mathrm{a}}$ varies from $7.4 \mathrm{~mm}$ to $9.2 \mathrm{~mm}$, the $\mathrm{MF}$ increases from $54.8 \%$ to $64.4 \%$ as illustrated in Fig. 8(a). When $W_{\text {a }}$ varies from $6.4 \mathrm{~mm}$ to $8.0 \mathrm{~mm}$, MF increases from $55.2 \%$ to $63.2 \%$ as depicted in Fig. 8(b).

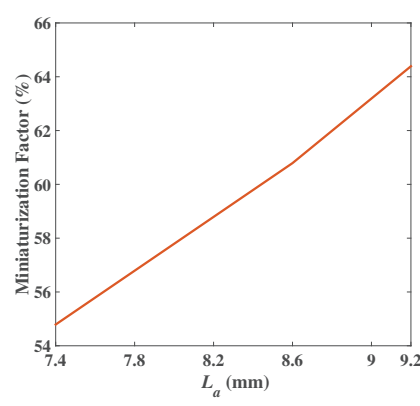

(a)

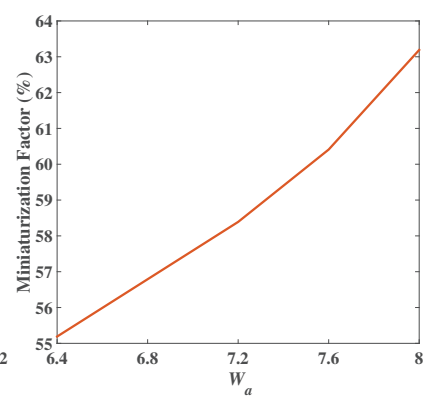

(b)
Fig. 8. Miniaturization factor of the proposed filter as a function of OLR parameters. (a) For $L_{\mathrm{a}}$. (b) For $W_{\mathrm{a}}$.

\section{SIW Filter Prototype and Measure- ment}

To verify the proposed design, a SIW filter loaded with OLRs working at $1.84 \mathrm{GHz}$ is fabricated and measured. The fabricated prototype is depicted in Fig. 9. The circuit-area of the filter prototype is $0.0147 \lambda_{\mathrm{g}}^{2}$, here $\lambda_{\mathrm{g}}$ is guided wavelength at $f_{0}$. The miniaturization-factor of the proposed prototype is determined as $63.2 \%$. The fabricated prototype is demonstrated using $\mathrm{R} \& \mathrm{~S}$ network analyzer.

The full-wave simulated response is compared with the measured one and illustrated in Fig. 10. The simulated and tested 3-dB bandwidths are calculated as $14.67 \%$ and $13.1 \%$, respectively. The Insertion Loss (IL) of the prototype is obtained as $0.51 \mathrm{~dB}$ with the Return Loss (RL) greater than $23 \mathrm{~dB}$. The performance comparison between proposed prototype and previously reported SIW filters is summarized and shown in Tab. 1. Compared to [3-12], the proposed prototype occupies smaller circuit-area, low insertion-loss and better matching. Therefore, the proposed filter is a suitable candidate for real-time application.

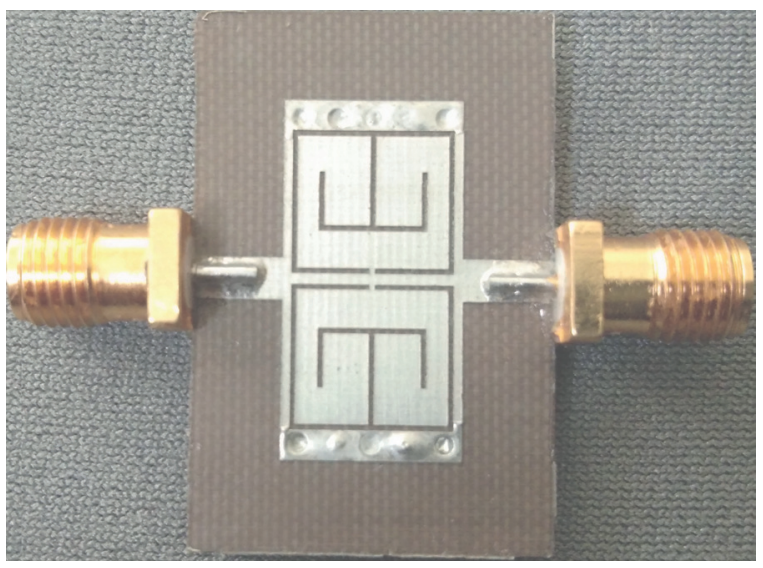

Fig. 9. Fabricated prototype of the proposed SIW filter.

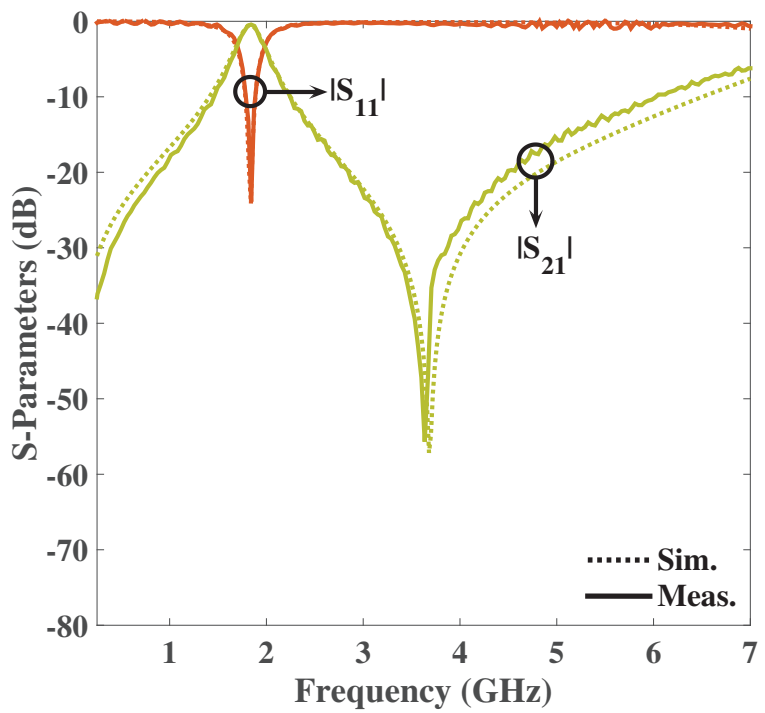

Fig. 10. Full-wave simulation and measurement performances of proposed prototype. 


\begin{tabular}{cccccc}
\hline Ref. & $\begin{array}{c}\text { CF } \\
(\mathrm{GHz})\end{array}$ & $\begin{array}{c}3-\mathrm{dB} \\
\mathrm{BW}(\%)\end{array}$ & IL (dB) & RL $(\mathrm{dB})$ & $\begin{array}{l}\text { Size } \\
\left(\lambda_{\mathrm{g}}{ }^{2}\right)\end{array}$ \\
\hline$[3]$ & 2.48 & 10.8 & 1.5 & 11.7 & 0.098 \\
\hline$[4]$ & 14.87 & 0.87 & 3.6 & 14.3 & 3.929 \\
\hline$[5]$ & 3.5 & 6 & 1.45 & 15 & 0.176 \\
\hline$[6]$ & 4.9 & 9.2 & 1.1 & 18 & 0.1521 \\
\hline$[10]$ & 28 & 3.6 & 2.2 & 16 & 1.455 \\
\hline$[11]$ & 8.25 & 1.1 & 3.3 & 15 & 4.0 \\
\hline$[12]$ & 1.8 & 9 & 1.53 & 15 & 0.04 \\
\hline This & $\mathbf{1 . 8 4}$ & $\mathbf{1 4 . 6 7}$ & $\mathbf{0 . 5 1}$ & $\mathbf{2 3 . 9}$ & $\mathbf{0 . 0 1 4 7}$ \\
Work & & & & &
\end{tabular}

Tab. 1. Performance Comparison Between Proposed and Reported SIW Filters. (CF: Center frequency, $\lambda_{\mathrm{g}}$ Guided wavelength at $\mathrm{CF}$, BW: Bandwidth, IL: Insertion loss, RL: Return loss)

\section{SIW Diplexer Prototype and Mea- surement}

The configuration of the SIW diplexer based on the filter structures is depicted in Fig. 11. The proposed diplexer is operated at $2.22 \mathrm{GHz}$ and $3.2 \mathrm{GHz}$ for S-band applications. Two SIW filter structures loaded by unit-cells with unequal dimensions are excited with a T-shaped microstrip feed line to produce lower and upper channels of the diplexer. The final layout dimensions are: $W_{\mathrm{c} 1}=18 \mathrm{~mm}, W_{\mathrm{c} 2}=18 \mathrm{~mm}, s=2 \mathrm{~mm}$, $d=1 \mathrm{~mm}, L_{11}=7.5 \mathrm{~mm}, L_{12}=7 \mathrm{~mm}, L_{13}=4 \mathrm{~mm}$, $L_{14}=5.75 \mathrm{~mm}, \quad W_{11}=0.25 \mathrm{~mm}, \quad W_{12}=0.25 \mathrm{~mm}$, $W_{13}=0.5 \mathrm{~mm}, \quad L_{21}=6 \mathrm{~mm}, L_{22}=5 \mathrm{~mm}, L_{23}=3 \mathrm{~mm}$, $L_{24}=4.25 \mathrm{~mm}, \quad W_{21}=0.25 \mathrm{~mm}, \quad W_{22}=0.25 \mathrm{~mm}$, $W_{23}=0.3 \mathrm{~mm}, L_{\mathrm{f} 1}=17.67 \mathrm{~mm}, L_{\mathrm{f} 2}=5 \mathrm{~mm}, L_{\mathrm{f} 3}=5 \mathrm{~mm}$, $W_{\mathrm{f} 1}=2.33 \mathrm{~mm}, W_{\mathrm{f} 2}=2.33 \mathrm{~mm}, W_{\mathrm{f} 3}=3 \mathrm{~mm}, t_{11}=0.5 \mathrm{~mm}$. Figure 12 illustrates the photograph of the fabricated SIW diplexer. The circuit-area of the diplexer prototype is $0.0147 \lambda_{\mathrm{g}}^{2}$, here $\lambda_{\mathrm{g}}$ is guided wavelength at lower channel.

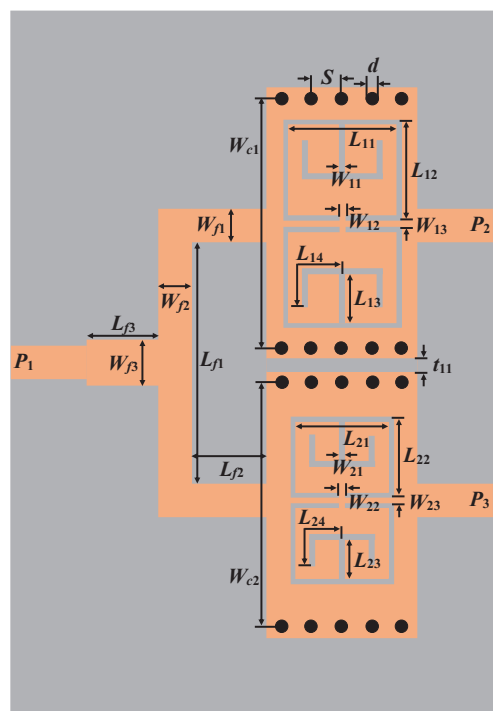

Fig. 11. Configuration of the proposed SIW diplexer.

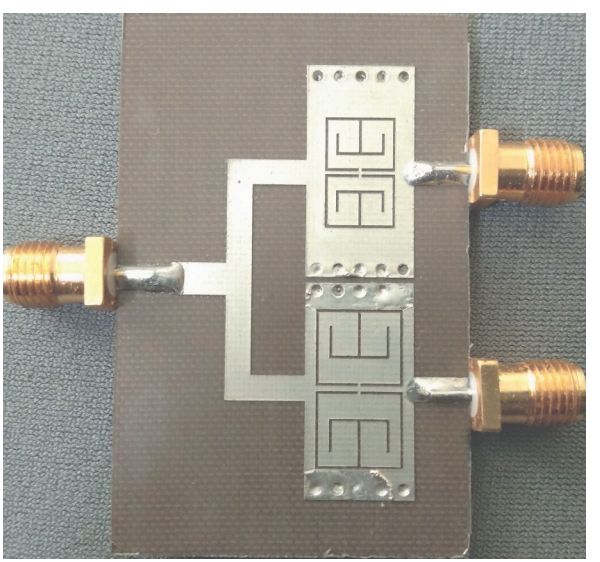

Fig. 12. Fabricated prototype of the proposed SIW diplexer.

The fabricated prototype is demonstrated using R \& $\mathrm{S}$ network analyzer. Figure 12 shows the comparison between simulation and measurement responses. The simulated (measured) insertion losses at lower and upper channels are $0.67 \mathrm{~dB}(0.97 \mathrm{~dB})$ and $0.8 \mathrm{~dB}(1.15 \mathrm{~dB})$, respectively. The measured return losses at lower and upper channels are greater than $-16 \mathrm{~dB}$ with minimum out-of-band suppression level of $20 \mathrm{~dB}$. The simulated and measured isolations at both the channels are greater than $22.8 \mathrm{~dB}$. Due to more commonend area between the channel circuits, the isolation of the diplexer is less than $23 \mathrm{~dB}$. However, the proposed planar diplexer exhibits smaller circuit area, low insertion loss and more bandwidth.

To demonstrate the advantages of our work, a comparative analysis based on performance indicators (insertion loss, isolation, bandwidth and circuit area) is summarized for the proposed and previously reported SIW diplexers as illustrated in Tab. 2. The proposed diplexer achieves a size reduction of $74.6 \%$ when compared to the most compact diplexer [20]. The isolation of the proposed prototype is smaller than [17-21], [23-25] and greater than [15, 16, 22, 26, 27]. However, compared to [15-27], the proposed diplexer occupies smaller circuit area, low insertion loss and more fractional bandwidth.

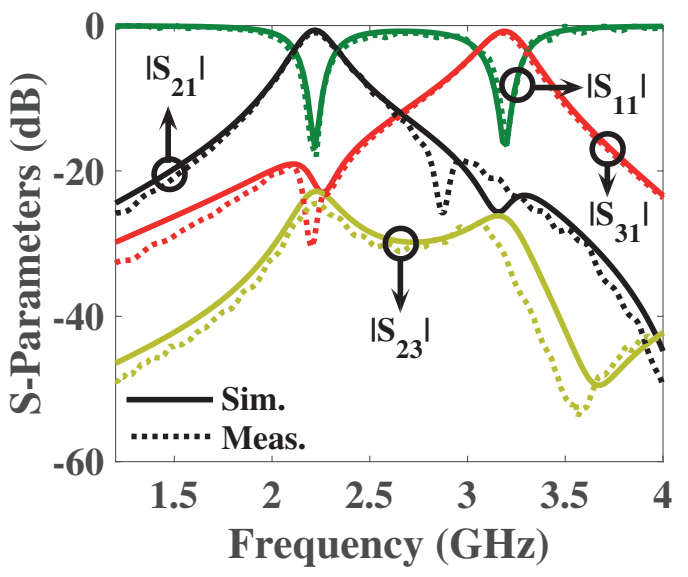

Fig. 13. Performances comparison of the proposed SIW diplexer. 


\begin{tabular}{ccccccc}
\hline Ref. & Technology/ Substrate $\epsilon_{\mathrm{r}}$ & CF $(\mathrm{GHz})$ & 3-dB BW (\%) & IL $(\mathrm{dB})$ & ISL $(\mathrm{dB})$ & Size $\left(\lambda_{\mathrm{g}}{ }^{2}\right)$ \\
\hline$[15]$ & LTCC/ 7.6 & $50 / 55.5$ & $2.5 / 4$ & $1.4 / 1.3$ & $>23$ & 1.871 \\
\hline$[16]$ & SIW/ 2.94 & $23.7 / 25.7$ & $5.91 / 5.45$ & $1.64 / 2.2$ & $>23$ & 8.72 \\
\hline$[17]$ & SIW/ 2.2 & $12 / 14$ & $4.9 / 5.65$ & $1.34 / 1.41$ & $>27$ & 2.77 \\
\hline$[18]$ & SIW/ 2.2 & $25 / 26.8$ & $2.8 / 1.8$ & 1.7 & $>30$ & 9 \\
\hline$[19]$ & SIW/ 2.2 & $9.75 / 10.25$ & $1 / 0.97$ & $4 / 7$ & $>30$ & 3 \\
\hline$[20]$ & Microstrip/ 10.8 & $1.8 / 1.9$ & $4 / 4$ & $2.88 / 2.95$ & $>50$ & $0.378^{\#}$ \\
\hline$[21]$ & SIW/ 10.8 & $1.788 / 1.917$ & - & $2.86 / 2.91$ & $>50$ & $3.42^{\#}$ \\
\hline$[22]$ & SIW/ 3.5 & $7.8 / 10.4$ & - & $1.7 / 2.22$ & $>16.8$ & $0.756^{\#}$ \\
\hline$[23]$ & SIW/ 3.5 & $5 / 5.25$ & $1.95 / 2.08$ & $2.2 / 2.4$ & $>45$ & 2.121 \\
\hline$[24]$ & SIW/ 3.55 & $10.5 / 13.5$ & $3.71 / 1.7$ & $1.3 / 1.35$ & $>42$ & 2.782 \\
\hline$[25]$ & SIW/ 2.2 & $9.5 / 10.5$ & $2.95 / 3.21$ & $2.62 / 2.34$ & $>45$ & 3.56 \\
\hline$[26]$ & SIW/ 2.33 & $6.16 / 7.72$ & $5.25 / 5.1$ & $0.83 / 0.77$ & $>22$ & 0.88 \\
\hline$[27]$ & SIW/ 2.2 & $8 / 12$ & $2.94 / 1.75$ & $1.84 / 2.88$ & $>20$ & 1.54 \\
\hline This Work & SIW/ 2.33 & $\mathbf{2 . 2 2 / 3 . 2}$ & $\mathbf{9 . 0 / 6 . 8 7}$ & $\mathbf{0 . 6 7 / 0 . 8}$ & $>\mathbf{2 2 . 8}$ & $\mathbf{0 . 0 9 6}$ \\
\hline
\end{tabular}

Tab. 2. A comparative analysis of proposed and previously reported SIW diplexers. (CF: Center frequency, $\lambda_{\mathrm{g}}$ : Guided wavelength at lower frequency, BW: Bandwidth, IL: Insertion loss, ISL: Isolation, \#: Area calculated based on the available dimensions)

\section{Conclusions}

This paper presents a novel miniaturized substrateintegrated waveguide (SIW) filter loaded with a pair of unitcell resonators. The unit-cell is formed by face-to-face connected open-loop resonators. The proposed unit-cells constitute an electric-dipole behaviour and produce a passband smaller than the waveguide frequency. This decrease in operating frequency allows us to achieve size miniaturization. The transmission responses are investigated by an equivalent circuit-model. This filter structure is applied to develop a miniaturized SIW diplexer. Two SIW filter structures loaded with unit-cells are designed and fed with a T-shaped microstrip line to achieve lower and upper channels of the diplexer. To demonstrate our claim, both SIW bandpass filter and diplexer are developed and fabricated. The simulated and measured responses demonstrate good agreement. The fabricated prototypes exhibit low insertion-loss, high-selectivity and miniaturization due to evanescent-mode propagation and subwavelength resonators.

\section{Acknowledgments}

This work is partially supported by the National Natural Science Foundation of China Grant 61471258 and University Key Research Project of Guangdong Province under Grant 2018 KZDXM063.

\section{References}

[1] HONG, J. S., LANCASTER, M. J. Microstrip Filters for RF/Microwave Applications. New York (USA): John Wiley \& Sons, 2001, DOI: $10.1002 / 0471221619$
[2] DESLANDES, D., WU, K. L. Accurate modeling, wave mechanisms, and design considerations of a substrate integrated waveguide. IEEE Transactions on Microwave Theory and Techniques 2006, vol. 54, no. 6, p. 2516-2526. DOI: 10.1109/TMTT.2006.875807

[3] WU, L., ZHOU, X., YIN, W. Evanescent-mode bandpass filters using folded and ridge substrate integrated waveguides (SIWs). IEEE Microwave and Wireless Components Letters 2009, vol. 19, no. 3, p. 161-163. DOI: 10.1109/LMWC.2009.2013739

[4] LI, R., TANG, X., XIAO, F. Design of substrate integrated waveguide transversal filter with high selectivity. IEEE Microwave and Wireless Components Letters, 2010, vol. 20, no. 6, p. 328-330. DOI: 10.1109/LMWC.2010.2047518

[5] ZHANG, Q., YIN, W., HE, S, et al. Compact substrate integrated waveguide (SIW) bandpass filter with complementary split-ring resonators (CSRRs). IEEE Microwave and Wireless Components Letters, 2010, vol. 20, no. 8, p. 426-428. DOI: 10.1109/LMWC.2010.2049258

[6] SHEN, W., YIN, W., SUN, X. Compact substrate integrated waveguide (SIW) filter with defected ground structure. IEEE Microwave and Wireless Components Letters, 2011, vol. 21, no. 2, p. 83-85. DOI: 10.1109/LMWC.2010.2091402

[7] ZHANG, P., LI, M. Cascaded trisection substrate-integrated waveguide filter with high selectivity. Electronics Letters, 2014, vol. 50, no. 23, p. 1717-1719. DOI: 10.1049/el.2014.3456

[8] LEE, B., LEE, T., LEE, K., et al. K-band substrate-integrated waveguide resonator filter with suppressed higher-order mode. IEEE Microwave and Wireless Components Letters, 2015, vol. 25, no. 6, p. 367-369. DOI: 10.1109/LMWC.2015.2421313

[9] JIA, D., FENG, Q., XIANG, Q., et. al. Multilayer substrate integrated waveguide (SIW) filters with higher-order mode suppression. IEEE Microwave and Wireless Components Letters, 2016, vol. 26, no. 9 , p. 678-680. DOI: 10.1109/LMWC.2016.2597222

[10] HE, Z., YOU, C., LENG, S., et al. Compact inline substrate integrated waveguide filter with enhanced selectivity using new non-resonating node.Electronics Letters, 2016, vol. 52, no. 21, p. 1778-1779. DOI: $10.1049 / \mathrm{el} .2016 .2712$

[11] KHAN, A., MANDAL, M. Narrowband substrate integrated waveguide bandpass filter with high selectivity. IEEE Microwave and Wireless Components Letters, 2018, vol. 28, no. 5, p. 416-418. DOI: 10.1109/LMWC.2018.2820605 
[12] AZAD, A., MOHAN, A. Single- and dual-band bandpass filters using a single perturbed SIW circular cavity. IEEE Microwave and Wireless Components Letters, 2010, vol. 29, no. 9, p. 201-203. DOI: 10.1109/LMWC.2019.2893379

[13] SERKAN, S., REZAEIEH, S. A design method for substrate integrated waveguide electromagnetic bandgap (SIW-EBG) filters. $A E U$ - International Journal of Electronics and Communications, 2013, vol. 67, no. 11, p. 981-983. DOI: 10.1016/j.aeue.2013.05.009

[14] Clara, M. G., HinOJOSA, J., MELCON, A. A. Design of wide band-pass substrate integrated waveguide (SIW) filters based on stepped impedances. AEU - International Journal of Electronics and Communications, 2019, vol. 100, p. 1-8. DOI: 10.1016/j.aeue.2018.12.022

[15] TSAI, W. L., SHEN, T. M., CHEN, B., et al. Design of singlebranch laminated waveguide diplexers using modal orthogonality. IEEE Transactions on Microwave Theory and Techniques, 2013, vol. 61, no. 12, p. 4079-4089. DOI: 10.1109/TMTT.2013.2287476

[16] KORDIBOROUJENI, Z., BORNEMANN, J. Substrate integrated waveguide diplexer with dual-mode junction cavity. In $2015 \mathrm{Eu}$ ropean Microwave Conference (EuMC), 2015, p. 753-756. DOI: 10.1109/EuMC.2015.7345873

[17] ZHOU, K., ZHOU, C., WU, W. Compact SIW diplexer with flexibly allocated bandwidths using common dual-mode cavities. IEEE Microwave and Wireless Components Letters, 2018, vol. 28, no. 4, p. 317-319. DOI: 10.1109/LMWC.2018.2805881

[18] CHU, P., HONG, W., TUO, M., et al. Dual-mode substrate integrated waveguide filter with flexible response. IEEE Transactions on $\mathrm{Mi}$ crowave Theory and Techniques, 2017, vol. 65, no. 3, p. 824-830. DOI: 10.1109/TMTT.2016.2633346

[19] GARCIA-LAMPEREZ, A., SALAZAR-PALMA, M., YEUNG, S. H. Compact diplexer with dual-mode SIW resonators. In 2014 44th European Microwave Conference. Rome (Italy), 2014, p. 857-860. DOI: 10.1109/EuMC.2014.6986570

[20] NWAJANA, A. O., YEO, K. S. K. Microwave diplexer purely based on direct synchronous and asynchronous coupling. Radioengineering, 2016, vol. 25, no. 2, p. 247-252. DOI: 10.13164/re.2016.0247

[21] NWAJANA, A. O., DAINKEH, A., YEO, K. S. K. Substrate integrated waveguide (SIW) diplexer with novel input/output coupling and no separate junction. Progress In Electromagnetics Research M, 2018, vol. 67, p. 75-84. DOI: 10.2528/PIERM18021603

[22] QU, L., ZHANG, Y., LIU, J. et al. Three-state SIW diplexer with independently controllable centre frequencies. Electronics Letters, 2019, vol. 55, no. 9, p. 548-550. DOI: 10.1049/el.2018.8255

[23] SONG, K., ZHOU, Y., CHEN, Y., et al. High-isolation diplexer with high frequency selectivity using substrate integrate waveguide dual-mode resonator. IEEE Access, 2019, vol. 7, p. 116676-116683. DOI: 10.1109/ACCESS.2019.2926121

[24] IQBAL, A., TIANG, J. J., LEE, C. K., et al. Tunable substrate integrated waveguide diplexer with high isolation and wide stopband. IEEE Microwave and Wireless Components Letters, 2019, vol. 29, no. 7, p. 456-458. DOI: 10.1109/LMWC.2019.2916609

[25] SU, Z. L., XU, B. W., ZHENG, S. Y., et al. High-isolation and widestopband SIW diplexer using mixed electric and magnetic coupling. IEEE Transactions on Circuits and Systems II: Express Briefs, 2020, vol. 67, no. 1, p. 32-36. DOI: 10.1109/TCSII.2019.2903388

[26] PRADHAN, N. C. SUBRAMANIAN, K. S., BARIK, R. K., et al. Design of a compact SIW diplexer with square cavities for C-band applications. In 2020 URSI Regional Conference on Radio Science (URSI-RCRS). Varanasi (India), 2020, p. 1-4, DOI: $10.23919 /$ URSIRCRS49211.2020.9113580
[27] XIE, H., ZHOU, K., ZHOU, C., et al. High-isolation and widestopband SIW diplexer using mixed electric and magnetic coupling. IEEE Transactions on Circuits and Systems II: Express Briefs, 2020, p. 1-1, DOI: 10.1109/TCSII.2020.2992059

\section{About the Authors ...}

Rusan Kumar BARIK received the B.Tech degree in Electronic \& Communication Engineering from Biju Patnaik University of Technology, Rourkela, India in 2012, M.Tech degree in Communication Systems Design and Ph.D. degree in Electronics Engineering from Indian Institute of Information Technology, Chennai, Tamil Nadu, India in 2015 and 2018, respectively. He joined the Department of Electronic \& Communication Engineering, Christ University Bangalore, India, as an assistant professor in 2018. He is currently a PostDoctoral Researcher with the Southern University of Science and Technology, Shenzhen, China. His research interests include multiband microwave passive devices, multiband antennas, and SIW components.

Qingsha S. CHENG received the B.Eng. and M.Eng. degrees from Chongqing University, Chongqing, China, in 1995 and 1998, respectively, and the Ph.D. degree from McMaster University, Hamilton, ON, Canada, in 2004. In 1998, he joined the Department of Computer Science and Technology, Peking University, Beijing, China. In 1999, he joined the Department of Electrical and Computer Engineering, McMaster University, where he worked as a postdoctoral fellow, a research associate, and a research engineer. He is currently an Assistant Professor with the Department of Electrical and Electric Engineering, Southern University of Science and Technology, Shenzhen, China. His research interests include surrogate modeling, CAD, modeling of microwave circuits, software design technology, and methodologies for microwave CAD.

Nrusingha Charan PRADHAN received the B.Tech. degree from Biju Patnaik University of Technology, India, in 2013, and the M.Tech degree in electronics engineering from Pondicherry Central University, Puducherry, India, in 2016. He was with the Integrated Test Range, Defence Research and Development Organisation, Chandipur, India (DRDO-ITR) for a period of two year. He is currently a Research Scholar with the Department of Electronics and Communication Engineering, National Institute of Technology, Tiruchirappalli, India. He has 3 technical papers. His current research interests include microwave integrated circuits, Substrate Integrated Wave Guide Components for Millimeter Wave Applications. Mr. Pradhan is a Student Member of the IEEE AP Society, the MTT Society.

Sholampettai Submaranian KARTHIKEYAN received the Ph.D. degree from IIT Guwahati, India, in 2011. He has 13 years of educational activity and research experience in the area of RF and microwave. He was the Short-Term academic foreign visit U.K and France. He is currently Assistant Professor with the Department of Electronics and Communica- 
tion Engineering, National Institute of Technology, Tiruchirappalli, India. He has authored or co-authored more than 100 scientific research papers and technical reports. His current research interests include microwave integrated circuits, biological effects of microwaves, computer-aided design of MICS, metamaterials/frequency selective surfaces (FSSs), fractal antennas, MIC antennas, metamaterial antennas, and substrate-integrated waveguides. Dr. Karthikeyan is a Chair of the IEEE-APS Society Madras chapter. He is a member of the IEEE, IEEE MTT-S, and IEEE AP-S. He is a Life Member of the ISTE. 